\title{
EVALUATION OF HUMAN MANDIBULAR PREMOLARS ROOT CANAL ANATOMY IN EGYPTIAN POPULATIONS USING CONE BEAM COMPUTED TOMOGRAPHY
}

\author{
Dalia Abd-Allah Mohamed* and Asmaa Youssry Abdallah**
}

\begin{abstract}
Introduction: Understanding root canal morphology is important to achieve successful root canal treatment (RCT). Studies on mandibular premolars showed that, there is a significant variation in the root canal anatomy between different ethnicities. Therefore, this retrospective study aimed to evaluate the root canal anatomy of mandibular premolars in Egyptian population using cone-beam computed tomography (CBCT).
\end{abstract}

Materials and Methods: 248 CBCT scans were evaluated and the anatomy of 392 mandibular first and 384 second premolars was classified according to Vertuci's classification. Data was statistically analyzed using SPSS software to calculate the incidences of root and canal number, each canal type, bilateral symmetry, and the association between gender and variation in root canal morphology.

Results: First and second premolars with two roots were found in $1.8 \%$ and $1 \%$ of scans respectively. Most of the mandibular first $(80.1 \%)$ and second premolars $(93.5 \%)$ showed (type I) root canal morphology followed by, type II (6.4\%) and type V $(2.1 \%)$ in the first and second premolars respectively. While, Type VIII showed the least frequency in both premolars. Only the second premolars showed a statistically significant association between gender and both canal type and number. Bilateral symmetrical anatomy was observed more in the second premolar $(94.8 \%)$ than the first premolar $(85.7 \%)$.

Conclusions: Mandibular premolars in Egyptian population showed great variation in root canal configuration. Therefore, preoperative CBCT evaluation is advantageous to avoid missing of existing extra canals during RCT. New classification systems for root canal morphology is highly recommended in further studies.

KEY WORDS: CBCT, Mandibular premolars, Root canal anatomy, Vertucci

* Lecturer in Endodontics, Faculty of Dentistry, Suez Canal University, Egypt.

** Lecturer in Oral Radiology, Faculty of Dentistry, Suez Canal University, Egypt. 


\section{INTRODUCTION}

Complete disinfection and three-dimensional tight seal of the root canal system possess a great clinical challenge during endodontic treatment. ${ }^{[1]}$ This is because of the fact that, the root does not usually contain an easy, single, uniformly tapered canal. Instead, the internal root anatomy is mostly complex including; additional canals, anastomosis, ramifications and other irregularities. ${ }^{[1,2]}$

Ignoring this complex anatomy has a negative impact on treatment prognosis. Infected canals or areas that harbor bacterial and/or necrotic debris would be missed by instrumentation, irrigation and obturation, with subsequent development of apical periodontitis. ${ }^{[1]}$ Therefore, studying the root canal anatomy prior to treatment is of prime importance to achieve success.

Conventional two-dimensional preoperative periapical radiography was traditionally used to identify root canal anatomy. ${ }^{[3-5]}$ However, it cannot give accurate details because of distortion and structures superimposition. ${ }^{[3,6]}$ Cone beam computed tomography (CBCT) was introduced in endodontics since 1990. This provides three-dimensional high-resolution images of pulp space anatomy, with the possibility of removing the superimposed structures. ${ }^{[6]}$

Nowadays, CBCT gain much popularity in endodontic practice. It provides images in the axial, sagittal, and coronal planes with better quality than conventional computed tomography. ${ }^{[3]}$ Also, it offers the ability to measure dentine thickness, allows the clinician to modify the access and shaping procedures to reach all the canals without over thinning of the dentinal walls that may lead to strip perforations. In addition, it has a significantly lower cost and radiation dose to the patients when compared to medical micro-computed tomography $(\mu-\mathrm{CT}){ }^{[7]}$

Mandibular premolars have showed a high incidence of variations in root canal morphology. ${ }^{[2,3]}$ These teeth are tempting to have one root canal during tactile exploration clinically. If extra canal(s) exists, usually the buccal root canal is easily accessible, whereas locating the lingual root canal orifice(s) is highly challenging. This can be attributed mainly to the lingual inclination of the relatively small sized crowns. ${ }^{[1,2]}$ In addition, the splitting of the extra canal is frequently with an acute angle that adds more difficulty to its accessibility. ${ }^{[1]}$ Accordingly, mandibular premolars were considered of the most difficult teeth to treat in endodontics with high rate $(11.45 \%)$ of post treatment failures. ${ }^{[1,2]}$

Studies on different populations found that, the root canal morphology vary significantly with ethnicity, race and sex. ${ }^{[2,3]}$ Therefore, it was important in this retrospective cross-sectional study, to evaluate both mandibular premolars root canal anatomy in the Egyptian population using CBCT. Because, up to our knowledge, no studies of this type, have been previously carried out on the Egyptian population.

\section{MATERIALS AND METHODS}

Sample size calculation was performed using $\mathrm{G}^{*}$ Power software. The effect size was 0.53 using alpha $(\alpha)$ level of 0.05 and Beta $(\beta)$ level of 0.05 , i.e., power $=95 \%$; the estimated minimum sample size (n) was a total of 600 teeth $(\mathrm{N}=600)$ in $150 \mathrm{CBCT}$ scans. The present research was waived from the approval of the Research Ethics Committee (REC), number 273/2020, faculty of Dentistry, Suez Canal University, Egypt. The present retrospective study was performed on the CBCT records obtained from the archives of the Outpatient Clinic of the Oral Radiology Department, faculty of Dentistry, Suez Canal University, Ismailia city and from private clinic archives, Cairo. Out of respect for patient confidentiality, all personal information concerning the patients other than sex and age was hidden.

CBCT images of mandibular premolars were obtained during the period February 2018 to April 2020. The study was conducted on 248 CBCT scans of bilateral mandibular sides of both sexes 
and ranging in age from 18 to 25 years. The CBCT scans included in the present study had to reveal the entire region of the mandibular premolar teeth and be of high-quality images free from artifacts caused by metallic objects that may impair pulp chamber visualization. Inclusion criteria also included: presence of mandibular premolars with fully matured apices and without apical periodontitis and no RC fillings, posts, or full-crown restorations.

\section{Cone-Beam Computed Tomography scanning protocol}

All CBCT images was acquired using a SCANORA 3DX scanner (Scanora 3DX, Soredex, Finland). The field of view was fixed at 240x165mm for all images using standard resolution mode. The operating parameters were $90 \mathrm{KVp}, 10 \mathrm{~mA}$ and the scan time was about 6 seconds. The voxel size was $0.5 \mathrm{~mm}$ using Flat panel a-Si detector. The acquired data was transferred into DICOM format, then exported into On Demand 3D application software (On Demand Cybermed. Co., Seoul, Korea), for image analysis and measurements.

\section{Image analysis and assessment of the root and root canals of mandibular first and second premolars}

Serial axial, coronal, and sagittal CBCT images were acquired by an experienced radiologist according to the operation instructions. Reformatted images were examined by carefully rolling the toolbar from the floor of pulp chamber, orifice, till the root apex of each premolar. This was repeated two times with the same time interval between the assessments for both examiners. All the images were assessed by both authors (One radiologist and one endodontist) have more than 7 years of experience in interpreting CBCT images, any disagreements in the observation were discussed and if needed, analysis by a third blinded endodontist was done until the authors reached a consensus.

The primary outcome of the study was to identify the anatomy of the root canal system of mandibular first and second premolars. The secondary outcome was to evaluate the number of roots, bilateral symmetry and correlation between sex and root canal configuration in these teeth.

Mandibularpremolars were carefully investigated by both authors independently. Vertucci's [8] classification was used to determine the type of root canal morphology. Vertucci's classification was defined as follows: type I (1), type II (2-1), type III (1-2-1), type IV (2), type V (1-2), type VI (2-1-2), type VII (1-2-1-2), and type VIII (3).

All data was written in prepared forms. Statistical analysis was performed using SPSS (Version 20.0; SPSS Inc, Chicago, IL) software. The frequencies (\%) of canals, roots incidence, any identified root canal type and bilateral symmetry in both teeth were calculated. The association between the patients' sex and bilateral symmetry, number of root or root canals, premolar configuration was determined using the Pearson's Chi-Square and Fisher's Exact Test. The level of significance was at 0.05 $(P \leq 0.05)$.

\section{RESULTS}

A Total of 248 CBCT scans, including 392 first premolars 172 males (43.9\%) and 220 females $(56.1 \%)$ and 384 second premolars 164 males $(42.7 \%)$ and 220 females (57.3\%) were evaluated. These Samples were from heterogeneous population including urban, Bedouin and Nubian

\section{Roots and Root canals configuration:}

Of the total 392 mandibular first premolars evaluated, 385 had one root $(98.2 \%)$ and 7 had two roots $(1.8 \%)$. The majority $337(86 \%)$ had one canal, $52(13.3 \%)$ had two canals and, 3 of them $(0.8 \%)$ had three canals [Table 1$]$.

Of the 384 mandibular second premolars evaluated, 380 teeth (99\%) had a single root, whereas four premolars $(1 \%)$ had two roots; second premolars with one canal (364 teeth, 94.8\%) and three canals ( 5 teeth, $1.3 \%$ ) showed more prevalence than in the first premolars. whereas, less two canals prevalence (15 teeth, 3.9\%) was shown [Table 1]. 
Deep split at the junction between the middle and apical thirds was noted in almost double rooted mandibular premolars in this study.

\section{Variations in root canal system}

Type I was the most prevalent canal configuration in mandibular first premolar $(80.1 \%)$ and in mandibular second premolar $(93.5 \%)$ teeth. In mandibular first premolars, type II was the second most prevalent type $(6.4 \%)$ followed by type III (5.9\%) and type V (5.6\%). Whereas, type IV (1.3\%) and type VIII $(0.5 \%)$ were the least prevalent [Figure 1] [Table $2 \& 3$ ].

On the other hand, type V (2.1\%) was the second prevalent canal configuration in the mandibular second premolars. This was followed by type III $(1.8 \%)$ and type II (1.6\%). The least frequent canal configuration in the second premolars was Type VIII $(0.8 \%)$ with no appearance for type IV [Table 3]. While, type VI and VII were not found in either the first or the second mandibular premolars.

Additional configurations were found in one first premolar $(0.3 \%)$ having one root canal with three apical splits, and one double rooted second premolar $(0.3 \%)$ with an aberrant root canal morphology, having type III canals in the buccal root and an additional canal in the lingual root [figure 2]. [Table $2 \& 3]$.

TABLE (1) The frequency and percentage of the number of roots and canals in mandibular first and second premolar teeth

\begin{tabular}{|c|c|c|c|c|c|c|c|}
\hline \multirow{2}{*}{\multicolumn{3}{|c|}{ Mandibular }} & \multicolumn{4}{|c|}{ Root/Canal Number } & \multirow{3}{*}{$\begin{array}{c}\text { Chi-square } \\
\text { Sign. }\end{array}$} \\
\hline & & & \multirow{2}{*}{$\begin{array}{c}\text { One } \\
385 \\
(98.2 \%)\end{array}$} & \multirow{2}{*}{$\begin{array}{c}\text { Two } \\
7 \\
(1.8 \%)\end{array}$} & \multirow{2}{*}{$\begin{array}{c}\text { Three } \\
0 \\
(0 \%)\end{array}$} & \multirow{2}{*}{$\begin{array}{c}\text { Total } \\
392 \\
(100 \%)\end{array}$} & \\
\hline Fin & Roots & $\begin{array}{c}\mathrm{N} \\
(\%)\end{array}$ & & & & & \\
\hline 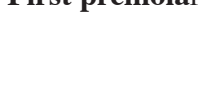 & Canals & $\begin{array}{c}\mathrm{N} \\
(\%)\end{array}$ & $\begin{array}{c}337 \\
(86.0 \%)\end{array}$ & $\begin{array}{c}52 \\
(13.3 \%)\end{array}$ & $\begin{array}{c}3 \\
(0.8 \%)\end{array}$ & $\begin{array}{c}392 \\
(100 \%)\end{array}$ & $<0.001 * * *$ \\
\hline \multirow{2}{*}{$\begin{array}{l}\text { Second } \\
\text { premolar }\end{array}$} & Roots & $\begin{array}{c}\mathrm{N} \\
(\%)\end{array}$ & $\begin{array}{c}380 \\
(99.0 \%)\end{array}$ & $\begin{array}{c}4 \\
(1.0 \%)\end{array}$ & $\begin{array}{c}0 \\
(0 \%)\end{array}$ & $\begin{array}{c}384 \\
(100 \%)\end{array}$ & $<0.001 * * *$ \\
\hline & Canals & $\begin{array}{c}\mathrm{N} \\
(\%)\end{array}$ & $\begin{array}{c}364 \\
(94.8 \%)\end{array}$ & $\begin{array}{c}15 \\
(3.9 \%)\end{array}$ & $\begin{array}{c}5 \\
(1.3 \%)\end{array}$ & $\begin{array}{c}384 \\
(100 \%)\end{array}$ & $<0.001 * * *$ \\
\hline
\end{tabular}

**** significant at p<0.001; using Chi-squared test.

TABLE (2) Number and frequencies of different canal configurations in mandibular first premolars.

\begin{tabular}{|c|c|c|c|c|c|c|c|c|c|c|c|c|}
\hline \multirow{2}{*}{\multicolumn{2}{|c|}{ Gender }} & \multicolumn{10}{|c|}{ Mandibular First Premolar Canal Type } & \multirow{2}{*}{ Sign. } \\
\hline & & \multirow{3}{*}{$\begin{array}{c}\text { I } \\
141 \\
36 \%\end{array}$} & \multirow{3}{*}{$\begin{array}{c}\text { II } \\
9 \\
2.3 \%\end{array}$} & \multirow{3}{*}{$\begin{array}{c}\text { III } \\
10 \\
2.6 \% \\
\end{array}$} & \multirow{3}{*}{$\begin{array}{c}\text { IV } \\
2 \\
0.5 \%\end{array}$} & \multirow{3}{*}{$\begin{array}{c}\mathbf{V} \\
7 \\
1.8 \%\end{array}$} & \multirow{3}{*}{$\begin{array}{c}\text { VI } \\
0 \\
0 \% \\
\end{array}$} & \multirow{3}{*}{$\begin{array}{c}\text { VII } \\
0 \\
0 \% \\
\end{array}$} & \multirow{3}{*}{$\begin{array}{c}\text { VIII } \\
2 \\
0.5 \% \\
\end{array}$} & \multirow{3}{*}{$\begin{array}{c}\text { Other } \\
1 \\
0.3 \% \\
\end{array}$} & \multirow{3}{*}{$\begin{array}{c}\text { Total } \\
172 \\
43.9 \%\end{array}$} & \\
\hline & $\mathbf{N}$ & & & & & & & & & & & \multirow{2}{*}{$<0.001 * * * b$} \\
\hline Male & $\%$ & & & & & & & & & & & \\
\hline \multirow{2}{*}{ Female } & $\mathbf{N}$ & 173 & 16 & 13 & 3 & 15 & 0 & 0 & 0 & 0 & 220 & \multirow{2}{*}{$<0.001 * * * b$} \\
\hline & $\%$ & $44 \%$ & $4 \%$ & $3.3 \%$ & $0.8 \%$ & $3.8 \%$ & $0 \%$ & $0 \%$ & $0 \%$ & $0 \%$ & $\mathbf{5 5 . 9 \%}$ & \\
\hline \multirow{2}{*}{ Total } & $\mathbf{N}$ & 314 & 25 & 23 & 5 & 22 & $\mathbf{0}$ & $\mathbf{0}$ & 2 & 1 & 392 & \multirow{2}{*}{$<0.001 * * * a$} \\
\hline & $\%$ & $80.1 \%$ & $6.4 \%$ & $5.9 \%$ & $1.3 \%$ & $5.6 \%$ & $0.0 \%$ & $0.0 \%$ & $0.5 \%$ & $0.3 \%$ & & \\
\hline
\end{tabular}

*,**, *** mean significant difference between different types at $p<0.05,<0.01,<0.001$; respectively; a Kruskal-Wallis test; b Chi-square test 
TABLE (3) Number and frequencies of different canal configurations in mandibular second premolars.

\begin{tabular}{|c|c|c|c|c|c|c|c|c|c|c|c|c|}
\hline \multicolumn{2}{|c|}{ Gender } & \multicolumn{10}{|c|}{ Mandibular Second Premolar Canal Type } & \multirow{2}{*}{ Sign. } \\
\hline & & I & II & III & IV & $\mathbf{V}$ & VI & VII & VIII & other & Total & \\
\hline \multirow[t]{2}{*}{ Male } & $\mathbf{N}$ & 149 & 2 & 7 & 0 & 4 & 0 & 0 & 1 & 1 & 164 & $<0.001 * * * \mathrm{~b}$ \\
\hline & $\%$ & $38.8 \%$ & $0.5 \%$ & $1.8 \%$ & $0 \%$ & $1 \%$ & $0 \%$ & $0 \%$ & $0.3 \%$ & $0.3 \%$ & $42.7 \%$ & \\
\hline \multirow[t]{2}{*}{ Female } & $\mathbf{N}$ & 210 & 4 & 0 & 0 & 4 & 0 & 0 & 2 & 0 & 220 & $<0.001 * * * \mathrm{~b}$ \\
\hline & $\%$ & $54.7 \%$ & $1 \%$ & $0 \%$ & $0 \%$ & $1 \%$ & $0 \%$ & $0 \%$ & $0.5 \%$ & $0 \%$ & $57.3 \%$ & \\
\hline \multirow[t]{2}{*}{ Total } & $\mathbf{N}$ & 359 & 6 & 7 & 0 & 8 & 0 & 0 & 3 & 1 & 384 & $0.039 *$ a \\
\hline & $\%$ & $93.5 \%$ & $1.6 \%$ & $1.8 \%$ & $0 \%$ & $2.1 \%$ & $0 \%$ & $0 \%$ & $0.8 \%$ & $0.3 \%$ & & \\
\hline
\end{tabular}

*,**,** mean significant difference between different types at $p<0.05,<0.01,<0.001$; respectively; a Kruskal-Wallis test; b Chi-square test

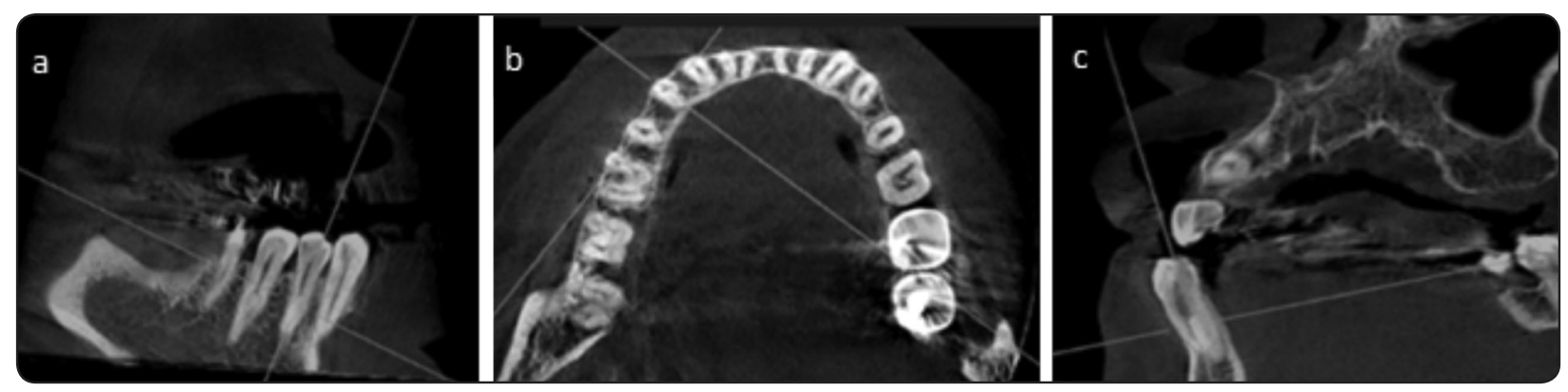

Fig. (1) Showing representative cone-beam computed tomography scans for single rooted mandibular right first premolar having type IV (2) root canal morphology in a) sagittal b) axial and c) coronal projections.
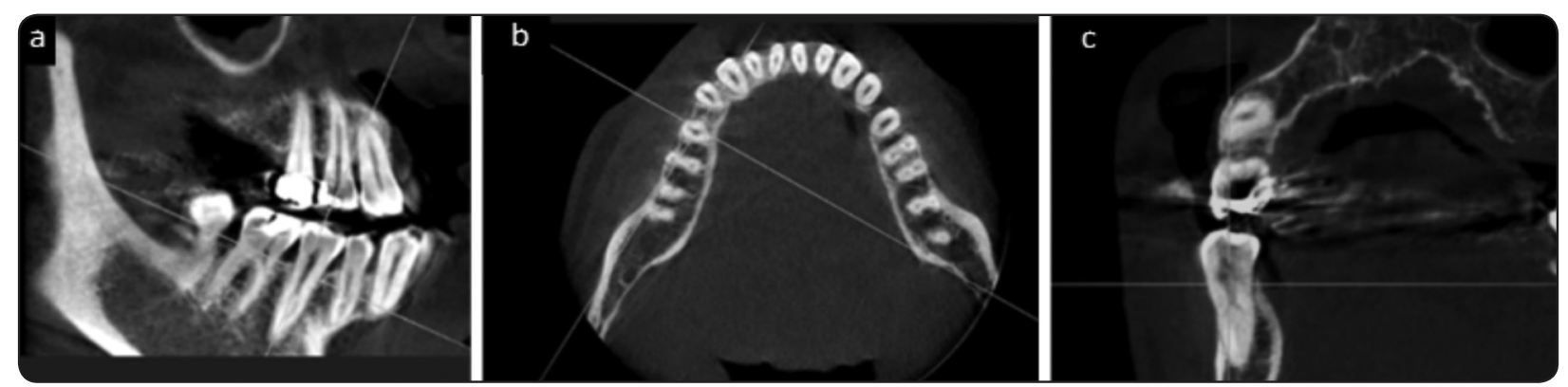

Fig. (2) Showing representative cone-beam computed tomography scans for double rooted mandibular right second premolar with a variation in root canal morphology at a) sagittal b) axial and c) coronal projections.

\section{SYMMETRY}

Among the 248 patients having bilateral mandibular first and second premolar teeth, $85.2 \%$ (334 cases; 146 males, 188 females) of first premolar teeth showed a symmetrical canal configuration, while $14.8 \%$ (58 cases; 28 males, 30 females) did not show any canal symmetry. On the other hand, more symmetry in canal configuration $94.8 \%$ (364 cases; 152 males, 212 females) was found in second premolar teeth, only $5.2 \%$ (20 cases; 12 males, 8 females) lacked bilateral canal symmetry.

\section{Gender}

Single-rooted mandibular first premolars were the most predominant root morphology in both 
genders. The prevalence of two-rooted mandibular first premolars in males ( 5 cases) was greater than that for females ( 2 cases). However, types II, III, V canal configurations were more likely to be observed in females. Interestingly, canal configuration Type VIII in first premolars was seen in male only $(0.5 \%)$. Though, Chi-Square and fisher exact tests for mandibular first premolars demonstrated no association $(p>0.05)$ between gender and number of roots, root canal configuration or their symmetric distribution (Table $2 \& 3$ ).

In mandibular second premolars, the prevalence of two-rooted mandibular first premolars in males (3 cases) was also Greater than that for females (1 case), type III was found only in male. Significant association was only found between gender and canal number $(p=0.05)$ and gender with canal configuration $(\mathrm{p}=0.043)$ [Table $2 \& 3$ ]

\section{DISCUSSION}

It is important for the endodontist to have through knowledge about the hidden canal anatomy to achieve successful RCT. For this reason, multiple in-vitro and in vivo methods have been used for studying root canal anatomy of mandibular premolars due to their great diversity and complexity. ${ }^{[2,3]}$ Unfortunately, the anatomy of mandibular premolars in the Egyptian population was underestimated in the previous studies. ${ }^{[2,3,9]}$ Only one in-vitro study on the Egyptian mandibular first premolars using the clearing technique was found in literature. ${ }^{[10]}$

Despite of the simplicity and convenient of different in-vitro methods used, they include a destructive evaluation of extracted teeth that lacks information about age, gender and bilateral symmetrical presence in patient. ${ }^{[2,3,4,10]}$ Moreover, teeth selection is biased by only choosing sound teeth due to difficulty to determine the tooth notation in destructed teeth. ${ }^{[3,11]}$ Accordingly, that might be the reason of our results inconsistency with most of the previous in-vitro studies including the previous Egyptian one. ${ }^{[10]}$
According to several studies CBCT is a more reliable method to assess the root canal morphology, as it offers a greater or equal accuracy to that obtained from, clearing and dye penetration technique but in a real time, informative and noninvasive way. ${ }^{[3,6,9,12,13]}$ In the current study, we included a larger number of CBCT scans from heterogeneous, Egyptian populations (urban, Bedouin and Nubian) as well as the mandibular second premolars that were not evaluated in the previous study. ${ }^{[10]}$

Our results were in agreement with Cleghorn et al. ${ }^{[2]}$ who stated that $98 \%$ of 4,462 mandibular first premolars were single-rooted, while the doublerooted prevalence was $1.8 \%$. Similar incidence was also found in the Iranian, ${ }^{[14]}$ and Chinese populations. ${ }^{[15]}$ However, higher double root prevalence was reported by Alhadainy ${ }^{[10]}$ in a previous in-vitro Egyptian study (3.2\%), Kottor et al. ${ }^{[3]}$ in their review article on 12,752 first premolars (2.63\%) and in three recent CBCT studies on the Iranian $(4.1 \%),{ }^{[13]}$ Saudi $(3.1 \%),{ }^{[16]}$ and Italian $(5.2 \%)$ populations. ${ }^{[17]}$

The absence of three rooted first premolars in our study came in agreement with the previous studies where rare incidence was reported. ${ }^{[2,3]}$ Few published studies on the French, ${ }^{[18]}$ Indian, ${ }^{[19]}$ and Saudi, ${ }^{[16,20]}$ populations found three roots incidence of $3,0.2$ and $2 \%$ respectively. This proves that root canal morphology differs significantly with different ethnics.

The existence of two (13.3\%) and three canals $(0.8 \%)$ in the first mandibular premolars in our study was in range found by other CBCT studies on the Chinese, ${ }^{[15,21]}$ Indian, ${ }^{[11]}$ Iranian, ${ }^{[22,23]}$ and German populations, ${ }^{[24]}$ where they found (10\% $22 \%),(0.2 \%-1.5 \%)$ two and three canal incidences respectively. On the other hand, previous in-vitro studies on American, Indian, Turkish, Iranian, Jordanian, Senegalese and Saudi populations showed more extra canal incidence, where the two and three canal prevalence reached up to (26$62.5 \%)$ and $(2-5 \%)$ respectively. ${ }^{[8,25,26,28,14,27,5,20]}$ 
The mandibular second premolars surveyed in our study showed less two rooted morphology (1\%) and two canals incidence $(3.9 \%)$ than the first premolars, which was similar to literature. ${ }^{[3]}$ However, more three canals incidence $(1.3 \%)$ was found in the second premolars with similar absence of three roots existence. Vyoma et al. ${ }^{[11]}$ using CBCT found similar $2^{\text {nd }}$ mandibular premolars two canal incidence in the Indian population (4\%). While other in vitro studies on the Turkish, ${ }^{[26,28]}$ Indian, ${ }^{[25]}$ Iranian, ${ }^{[14]}$ and Jordanian populations reported higher incidence (6.4-29\%) respectively. ${ }^{[27]}$

Though, the literature scarcely reported three canals in the mandibular second premolars, ${ }^{[3,11,23]}$ their incidence in our study $(1.3 \%)$ was in range of limited studies that reported their existence (0.4$2 \%$ ) on the Iranian, ${ }^{[22]}$ Senegalese, ${ }^{[5]}$ and Jordanian populations. ${ }^{[27]}$ Great variations in the surveyed root canal configuration of both premolars were found in our study. Type I was the most predominant canal configuration in mandibular first $(80.1 \%)$ and second $(93.5 \%)$ premolars teeth, that came in agreement with most studies in literature. ${ }^{[2,3]}$

Similar to our study, type II and III frequencies were found the second and third most prevalent anatomy in the Turkish, ${ }^{[28]}$ and Saudi populations,,${ }^{[16]}$ using clearing and CBCT methods respectively. In contrary, a published review ${ }^{[3]}$ and plenty of studies ${ }^{[8,10,13-15,19,20,27,29,30]}$ showed that mandibular first premolars had type $\mathrm{V}$ ranging from $4.1 \%$ [30] to $24 \%{ }^{[8]}$ and, type IV ranging from $11.5^{[17]}$ to $25 \%$ ${ }^{[31]}$ configurations to be the second most prevalent canal anatomies.

Regarding the second mandibular premolars, we found type V (2.1\%) the second most prevalent canal configuration, similar to previous studies on the Spanish, ${ }^{[32]}$ American, ${ }^{[8]}$ Indian, ${ }^{[31]}$ Chinese,${ }^{[15]}$ Turkish, ${ }^{[26]}$ and Jordanian populations. ${ }^{[27]}$ On the other hand, other studies on the Iranian, Indian, Saudi and Korean populations recorded type $\mathrm{III}^{[11,13,14,25]}$ and II $^{[16,25,30]}$ to be the second most prevalent anatomy in lower second premolars. The absence of mandibular second premolars having type IV in our results was in agreement with previous studies. $[8,13,14,24,26,30,32]$ Though, it was the second most predominant anatomy in the Italian, ${ }^{[17]}$ and Turkish populations. ${ }^{[28,33]}$ Also, it was presented with high incidence in other studies. ${ }^{[14-16,25,27,28,31]}$

Generally, the incidence of type VI, VII and VIII in the mandibular first and second premolars were rare in literature. ${ }^{[2,3,13,17]}$ Still, the low incidence of mandibular first premolars with type VIII $(0.5 \%)$ in our study was in range found by other CBCT studies in Turkish $(0.06 \%),{ }^{[33]}$ German $(0.2 \%),{ }^{[24]}$ Chinese (0.6\%), ${ }^{[15]}$ Indian (1\%), ${ }^{[11]}$ and Saudi (1.5\%) populations. ${ }^{[16]}$ Strikingly, some of these CBCT studies showed greater incidence of type VIII in the second mandibular premolars $(1.7,0.3$ and $0.2 \%$ respectively) than in their first counterparts similar to our study. ${ }^{[16,24,33]}$

Unfortunately, other complex anatomies were found in our studies, that couldn't be described using Vertucci's classification. ${ }^{[8]}$ First premolar with one root canal and three apical splits was also found by Chourasia et al. ${ }^{[20]}$ and was described as Type IX (1-3) by Sert and Bayirli. ${ }^{[28]}$ Also, the double rooted mandibular second premolar with unusual root canal morphology, could be described better using other classifications. ${ }^{[34,35]}$

The increased bilateral symmetric presence of the first than the second premolars was in agreement with Nasrin et al. ${ }^{[22]}$. Although the surveyed second premolars in our study showed an association of extra canal in male, no association was found in the Saudi, ${ }^{[16]}$ Iranian, ${ }^{[13]}$ or Italian populations. ${ }^{[17]}$

Limitation in our study is that, the CBCT scans were taken during standard dental practice not for endodontic purpose. Moreover, other parameters as the existence of radicular grooves, root curvature, anomalies in the Egyptian mandibular premolars and their proximity to mental and inferior alveolar nerve were not assisted. Therefore, further studies are required to evaluate theses parameters using 
recently introduced classifications, software, and with (limited FOV) for better resolution.

\section{Research Highlights}

Root canal treatment of mandibular premolars is challenging, and the possibility of extra roots and root canals existence should be considered. Unfortunately, no CBCT study evaluated the mandibular premolars morphology in the Egyptian population and generally second premolars were underestimated.

\section{CONCLUSIONS}

1) Mandibular premolars in Egyptian population showed great variation in root canal configuration.

2) Type I is most common and type VIII is the least observed.

3) Significant association between male and the incidence of extra canal types was observed only in the second premolars.

\section{REFERENCES}

1. Gutmann J, Fan B. Tooth morphology and pulpal access cavities. In: Berman LH, Hargreaves KM and Rotstein I editors: Cohen's Pathways of the Pulp 12th edition, St Louis. Missouri: Elsevier; 2021.chapter 7, p.746-853.

2. Cleghorn B, Christie W, Dong C. The root and root canal morphology of the human mandibular first premolar: a literature review. J Endod 2007: 33; 509-16.

3. Kottoor J, Albuquerque D, Velmurugan N, Kuruvilla J. Root Anatomy and Root Canal Configuration of Human Permanent Mandibular Premolars: A Systematic Review. Anat Res Int 2013; 2013: 254250.

4. Zaatar EI, Al-Kandari AM, Alhomaidah S, Al-Yasin IM. Frequency of endodontic treatment in Kuwait: radiographic evaluation of 846 endodontically treated teeth. J Endod 1997; 23: 453-56.

5. Mbaye M, Touré B, Kane AW, Leye F, Bane K, Boucher Y. Radiographic study of the canal anatomy of mandibular premolars in a Senegalese population. Dakar Med 2008; 53:267-71.
6. Michetti J, Maret D, Mallet J, Diemer F: Validation of cone beam computed tomography as a tool to explore root canal anatomy. J Endod 2010; 36: 1187-90.

7. Loubele M, Bogaerts R, van Dijck E: Comparison between effective radiation dose of CBCT and MSCT scanners for dentomaxillofacial applications. Eur J Radiol 2009; 71: 461-68.

8. Vertucci FJ. Root canal anatomy of the human permanent teeth. Oral Surg Oral Med Oral Pathol 1984;58:589-99

9. Sharaan ME and Elrawdy AM. An evaluation of mandibular molars root canal morphology using cone-beam computed tomography in an Egyptian subpopulation. Tanta Dent J 2017; 14:220-4.

10. Alhadainy HA. Canal configuration of mandibular first premolars in an Egyptian population. J Adv Res 2013; $4: 123-8$.

11. Vyoma S, Rupal V, Shraddha C, Zarna S, Pruthvi P, Kinha T. Evaluation of root and canal morphology of mandibular premolars in urban Indian population: an in-vivo cone beam computed tomographic study. Int J Med and Dent Sci. 2016; 5:1214-21.

12. Khademi A, Mehdizadeh M, Sanei M, Sadeqnejad H, Khazaei S. Comparative evaluation of root canal morphology of mandibular premolars using clearing and cone beam computed tomography. Dent Res J (Isfahan) 2017; 14: $321-5$

13. Hajihassani N, Roohi N, Madadi K, Bakhshi M, Tofangchiha M. Evaluation of Root Canal Morphology of Mandibular First and Second Premolars Using Cone Beam Computed Tomography in a Defined Group of Dental Patients in Iran. Scientifica (Cairo) 2017; 2017: 1504341.

14. Rahimi S, Shahi S, Yavari HR, Manafi H, Eskandarzadeh N. Root canal configuration of mandibular first and second premolars in an Iranian population. J Dent Res Dent Clin Dent Prospects 2007; 1:59-64.

15. Tian YY, Guo B, Zhang R, Yu X, Wang H, Hu T, Dummer PMH. Root and canal morphology of maxillary first premolars in a Chinese subpopulation evaluated using cone-beam computed tomography. Int Endod J 2012; 45:996-1003.

16. Alfawaz H, Alqedairi A, Al-Dahman YH, Al-Jebaly AS, Alnassar FA, Alsubait S, et al. Evaluation of root canal morphology of mandibular premolars in a Saudi population using cone beam computed tomography: A retrospective study. Saudi Dent J 2019 Jan; 31: 137-42 
17. Corbella S, Baruffaldi M, Perondi I, Taschieri S. Conebeam computed tomography investigation of the anatomy of permanent mandibular premolars in a cohort of Caucasians. J Invest Clin Dent 2019; 10:e12373.

18. Geider P, Perrin C, Fontaine M. Endodontic anatomy of lower premolars-apropos of 669 cases. J Odontol Conserv 1989; (10):11-15.

19. Iyer VH, Indira R, Ramachandran S, Srinivasan MR. Anatomical variations of mandibular premolars in Chennai population. Indian J Dent Res 2006;17: 7-10.

20. Chourasia H, Boreak N, Tarrosh M, Mashyakhy M. Root canal morphology of mandibular first premolars in Saudi Arabian southern region subpopulation. Saudi Endod J 2017; 7:77-81.

21. Lu TY, Yang SF, Pai SF. Complicated root canal morphology of mandibular first premolar in a Chinese population using the cross section method. J Endod 2006; 32:932-36.

22. Nasrin R, Zohreh K, Mehrdad P. Evaluation of root anatomy and morphology of mandibular premolars with CBCT in Iran population. Int J Life Sci Pharma Res 2016; 6: $33-40$

23. ZareJahromi M, Mehdizade M, Shirazizade Z, Poursaeid E. Evaluation of mandibular premolars root canal morphology by cone beam computed tomography. Caspian J Dent Res 2018; 7: 58-63.

24. Bürklein S, Heck R, Schäfer E. Evaluation of the Root Canal Anatomy of Maxillary and Mandibular Premolars in a Selected German Population Using Cone-beam Computed Tomographic Data. J Endod. 2017; 43:1448-52.

25. Sikri VK, Sikri P. Mandibular premolars: aberrations in pulp space morphology. Indian J Dent Res 1994; 5:9-14.

26. Çalişkan MK, Pehlivan Y, Sepetçioğlu F, Türkün M, Tuncer SŞ. Root canal morphology of human permanent teeth in a Turkish population. J Endod. 1995; 21: 200-4.
27. Awawdeh LA, Al-Qudah AA. Root form and canal morphology of mandibular premolars in a Jordanian population. Int Endod J 2008; 41: 240-8.

28. Sert S, Bayirli GS. Evaluation of the root canal configurations of the mandibular and maxillary permanent teeth by gender in the Turkish population. J Endod 2004; 30:391-8.

29. Khedmat S, Assadian H, Saravani AA. Root canal morphology of the mandibular first premolars in an Iranian population using cross-sections and radiography. J Endod 2010;36: 214-17.

30. Jang YE, Kim Y, Kim B, Kim SY, Kim HJ. Frequency of non-single canals in mandibular premolars and correlations with other anatomical variants: an in vivo cone beam computed tomography study. BMC Oral Health 2019 4; 19: 272.

31. Parekh V, Shah N, Joshi H. Root canal morphology and variations of mandibular premolars by clearing technique: an in vitro study. J Contemp Dent Pract. 2011;12: 318-21.

32. Llena C, Fernandez J, Ortolani PS, Forner L. Cone-beam computed tomography analysis of root and canal morphology of mandibular premolars in a Spanish population. Imaging Sci Dent 2014; 44: 221-27.

33. Ok E, Altunsoy M, Nur BG, Aglarci OS, Colak Ms Güngör E. A cone-beam computed tomography study of root canal morphology of maxillary and mandibular premolars in a Turkish population. Acta Odontol Scand 2014;72: 701-6.

34. Ahmed HM, Versiani MA, De-Deus G, Dummer PM. A new system for classifying root and root canal morphology. Int Endod J 2017;50: 761-70.

35. Wolf TG, Kim P, Campus G, Stiebritz M, Siegrist M, Briseño-Marroquín B. Dimensional Analysis and Systematic Review of Root Canal Morphology and Physiological Foramen Geometry of 109 Mandibular First Premolars by Micro-computed Tomography in a Mixed Swiss-German Population. J Endod 2020; 46:801-9. 